\title{
Public Transport and the Decline of the Traditional Retail Sector in South Africa
}

\author{
Tabukeli M. Ruhiiga \\ School of Environmental \& Health Sciences Mafikeng Campus North West University \\ Mmabatho 2735, South Africa \\ E-mail: tabukeli.ruhiiga@nwu.ac.za
}

KEYWORDS Household Shopping Patterns. Trip Frequencies. Passenger Transport. Economic Growth

\begin{abstract}
This paper reports the results of an investigation of the impact of recent developments in public transport on the traditional retail sector. Data collection was carried out based on four towns in the Eastern Cape Province selected on the basis of having a significant consumer market. For each of these centres, three localities located in 25-35-45kilometre radii were selected and in each of these, a random sample of 50 households was interviewed about their income distribution, shopping patterns, patronage of retail outlets and access to public transport. The data was analysed using frequency distributions and correlation. The findings indicate that access to public transport plays an indirect but critical role in the shopping patterns of households. The decline of the traditional retail sector has been facilitated by developments in transport and changing consumption trends at local, regional and global scales.
\end{abstract}

\section{INTRODUCTION}

The greatest volume of research work on transport is taken up with problems of providing the infrastructure, issues of optimizing service delivery in urbanised high population density areas, improving travel efficiencies, predicting travel demand and advising on planning interventions centred on national transport networks. To this end, transportation forecasting aims at estimating the number of vehicles (DOT 1998) or the population of people who will make use of a particular transport mode and its related facilities (CSIR 2005). The process begins with the collection of data on the current state of the transport industry-private, industrial, public and commercial across all the existing modes. Additional data on socio-economic indicators are mobilized in order to develop a traffic demand model. As part of a planning framework, transport forecasting has traditionally been built

Address for correspondence:

Tabukeli Musigi Ruhiiga,

Department of Geography and Environmental Sciences,

School of Environmental and Health Sciences,

Faculty of Agriculture, Science and Technology,

North West University,

Private Bag X2046,

Mmabatho 2735,

South Africa

Telephone: (+27) 183892310

Fax: (+27)183892637

E-mail: Tabukeli.ruhiiga@nwu.ac.za around five main principles or steps. Land use forecasting is normally concerned with a locality, part of, or a specific region as a critical input in development planning. Trip generation according to Mwakalonge (2011) has as the objective the predicting of the expected travel demand in a region and is used to compute the frequency of origins and or end points of trips in each sub-block of the entire planning area and classified in the context of the purpose of the trip. This has to include reference to the socio-economic profile of the population and existing land uses. The process of matching the origin of trips and their potential destinations, called trip distribution (Schurman et al. 2006), is often dealt with using the adjustments to the standard gravity model. Route assignment deals with the allocation trips between origin and destination by apportionment to specific modes of travel to a route.

Yet, while today sophisticated computer software exists for urban transport planning, provision of infrastructure and optimization of efficiencies in integrated transport systems, these approaches are often not suited for addressing problems of public passenger transport in nonurban environments. Indeed, academic research on the transport sector in Sub-Saharan Africafor example- has concentrated on rather narrow technical engineering issues and on urban transport systems and (Lombard et al. 2007; World Bank 2002) upon roads per se. To be beneficial to a wide sector of the continent's population, 
transport research also requires a detailed understanding of the economic, social and political environments in which transport takes place and interventions are made (Porter 2007). The responses of the transport sector in general, and of public passenger transport in particular to changes sweeping through the entire economic system cannot be ignored. Changes in incomefor example- exert a ripple effect on travel behaviour which in turn feeds into travel demand, consumption patterns and perception of time as a scarce resource. Beyond time, the resources necessary to fund and operate a public passenger transport system are underlain by the theory of scarcity (Verzola 2010; Anderson 2006) which advances the common view in mainstream economics that since resources are limited compared to their demand, an allocation mechanism is developed to ensure that such resources are put to the best use. If the provision of public transport by state and private operators is a response to perceived market demand, then market imperfections must by necessity have a direct impact on the dynamics of transport optimal pricing. The planning and provision of road transport networks in Sub-Saharan Africa- for example, has often been driven by political rather than efficiency considerations (Ruhiiga 2011). The mismatch between the location of dense non-urban settlements and the configuration of transport routes linking urban centres generates inefficiencies which providers of public passenger transport must bear. But the theory of efficiency has enlisted different interpretations in time from different disciplines. Efficiency in economic theory may refer to system performance as measured in terms of whether it represents the minimum average cost (Schiller 2008:483) or in terms of whether the imbedded investment is the most optimal in the context of returns per unit. Economic efficiency, unlike technical efficiency which deals with output performance of machines and industrial systems, remains a fluid theory due to limitations of precise measurement of inputs.

In a study of road connectivity and crop farming in Africa (Carruthers et al. 2008) report that bridges, rail lines, ports, and airports deliver economic and social benefits by connecting firms to international and regional markets, and by enabling individuals to reach water, fuel, schools, clinics, jobs, and relatives. Without reliable and competitively priced freight transport over sturdy infrastructure, nations have little hope of trading their goods on the most advantageous terms. If they cannot transport their produce to market from isolated rural areas, farmers will be unable to break out of subsistence agriculture. If they cannot transport their children to schools and clinics, the next generation will fare no better. Transport makes markets work. In a study in Belgium, Mayers and Proest (2002) show that transport pricing reform is necessary to reduce the effects of market imperfections on achieving optimal operating results.

In the case of South Africa, transport planning is embodied in its white paper on national transport (DOT 1996) laying out the key principles and expected long term outcomes of proposed state interventions in the transport sector. Service providers here include the state through affiliates of Transnet which also is the dominant player in the railway system; private and public companies that operate fleets of buses offering regular service on scheduled routes; operators of tour companies- with buses, minibuses and cars and, finally the thousands of private individuals that own and operate minibuses under the control of area-specific local transport associations. Little so far is known about the operations of this last category and its impact on passenger flows outside of the main urban centres and national routes. Ruhiiga (2000) reports that in rural areas with predominant African population apartheid regional planning has created a distorted settlement pattern that is not conducive to any form of economic activity. Implied in this brief survey are three features that have direct impact on the operations of the retail trade sector in South Africa. First is that the current road transport network in high population non-urban African areas are not optimally configured to facilitate connectivity between settlements and towns. Second, that public passenger transport- at least in South Africa- does not yet attract any significant research effort. Third, that understanding traffic flows in the context of connectivity and accessibility in which consumer are involved has to be against a background of a distorted settlement landscape.

The retail trade sector is the most widespread form of enterprise in Sub-Saharan Africa. The industry is classified into a traditional and a modern sector. The former tends to be small, is the oldest in the market, has a presence in both 
rural and urban settings, localised in its market presence, associated with low levels of technology, limited capitalisation, extremely low levels of participation in formal money markets, almost a total absence of business information systems usage and a simple management structure. The modern sector is localised in the main urban centres, operates on a large scale where individual outlets are commonly part of national and regional chain stores and does not suffer from the operational limitations noted for the traditional sector. Operating within the general view that business remains the engine of economic growth, a focus on retail firms should provide insights on some of the drivers of local economic growth. This is necessary in order to understand the drivers of economic growth (Naudé and Krugell 2004). The spatial ramifications of such drivers justify interest in how firms behave under relatively similar market environments. At another but parallel level, how the consumer market responds to rapid change ushered in by easier access to affordable public transport introduces interaction possibilities that generate a market space in a state of continual flux. In short the differences in the way the traditional sector and the modern sector respond to developments in the immediate market space is a key to their understanding of changing patterns of shopping behaviour.The focus on the retail sector has to be sensitive to major global changes taking place (Grewal and Levy 2009). In the European Union (EU), the USA and Canada, excess new competition from powerful market players is seeing the gradual eradication of small retail outlets at the local level. In emerging markets, the modern retail sector especially in general merchandizing and fresh food is increasing its market share by dispersing from traditional large cities into secondary urban areas thereby taking over business from traditional small business including the informal sector. Beyond these, Wrigley and Coe (2009) reports on the globalization of retailing and its impact on host economies. What is the state of current debate on the retail sector? From the Journal of Retailing, Grewal and Levy (2009) indicate key contemporary themes in the period 2001-2007. These centre on the growth of the internet and e-commerce, branding and customer loyalty, service success strategies and behavioural issues in pricing and patronage. The second approach centres around issues of internationalization of retailing (Coe and Wrigley 2007; Dawson 2007; Reardon and Berdegué 2002) driven mainly by an acceleration of retail direct foreign investment (FDI) in emerging markets- East Asia, Central and Eastern Europe, Latin America and South Africa. These changes have had a major effect on retail competitiveness, supply-chain dynamics, consumption practices, and responses of consumers, institutional and regulatory frameworks in host economies.

Both internationalization and globalization of retailing especially through European-American based transnational corporations (TNC's) has led to a significant literature in the last ten years on the responses of the traditional retail and modern retail sectors in host countries and the success or otherwise of these incursions (Humphrey 2007; Rodriguez et al. 2002) in Argentina and Faguenbaum et al. (2002) in Chile. But literature on the response of the domestic retail sector and its interface with the consumer market remains limited. In addition, the ability of large retail chains to challenge traditional retailing especially in fresh foods in low- income markets has not received much attention yet. It has been shown indeed that in some countries, the modern retail sector has successfully managed to outcompete these new arrivals forcing new entry strategies including twining between TCN's with local operators. The third approach centres on historical developments in the retail sector of individual countries and structural changes therein. This approach emphasizes the general decline of small retail outlets and the informal sector in the face of competition from the local 'modern retail' sector and the impact of new market technologies.

At the national scale, the decline of the small business sector and of the traditional retail trade in particular is linked to changing consumption lifestyles as evidenced by increasing sophistication of the consumer market. One major driver of these developments has been improvements in public transport and accessibility leading to greater mobility, exposure and an increase in shopping choice. Income distribution across many developing countries- in spite of the persistence of poverty- shows major changes in household disposable income including greater social assistance programmes. The penetration of big business into low-income markets (Reardon et al. 2003) traditionally the preserve of small retailers has created a level of competition not 
seen until in recent years. Access to a variety of credit facilities for the majority of households and individuals has had an upward spiral effect on consumption. Periodic retail sales data from Statistics South Africa (STATSA 2011a, 2011b) essentially represent only registered businesses which report results. Registered businesses are essentially only a fraction of the sector and hence such results do not capture true trends for the entire industry. At the level of South Africa, the decline of the traditional retail sector may be placed in three phases of business development each covering 10-15 years. Up to 1994, the retail sector across small, micro- and medium enterprises (SMME) was dominated by South Africans across different racial categories but Asian traders were restricted to Natal while African entrepreneurs dominated the former homelands and townships. After 1994, the lifting of restrictions on movement and trade led to the invasion of the rest of the country by Indian retailers mainly from Kwa-Zulu Natal Province and migrants from Pakistan, Bangladesh and Indonesia. Since 2000, there has been a third wave of Chinese nationals and thousands of African migrants. Each of these phases has had a radical impact on retail structure, ownership patterns and perhaps not observed in contemporary literature- a general marginalisation of indigenous South Africans to the periphery. In the meantime, there has been a diversification of White South Africans from traditional retailing into the professional services sector. Parallel to this has been the disappearance of a class of indigenous Africa retail family businesses save in the public transport, funerals and liquor store sectors. The colonisation of streets and pavements by hawkers in the name of self-employment is partly exploited by established retailers who also operate stalls at different sites in urban centres. The original calm, cleanliness, law and order associated with South African towns before 1990 is rapidly disappearing. On the surface therefore, the retail sector may present an image of a booming industry. The truth is that beyond well established large indigenous store chains-South Africans- are increasingly being displaced from traditional retailing.

How the urban based modern retail trade sector exploits opportunities created through public transport development, channel increased patronage from rural consumers, create essentially a captive market and the negative effects on the traditional retail trade sector remain an area of limited research coverage. The aim of this study is to focus on the interface between public transport access, the retail sector and changes in shopping behaviour. Several objectives are advanced; to describe developments in the retail sector in South Africa in the context of local, regional and global change, to compare responses of the modern and traditional sector to developments in public transport and changes in consumption behaviour and finally, to comment on the managerial implications of these developments. It is hypothesized that public transport developments have accelerated the decline of the traditional retail sector in South Africa.

\section{METHODOLOGY}

The study sites in the Eastern Cape Province are shown in Figure 2 while Figure 1 shows the main administrative units. Mthatha (31035'S, $28^{\circ} 47^{\prime}$ E), Engcobo (31040'S, 27059' E), Queenstown ( $31^{\circ} 53^{\prime}$ 'S, $\left.26^{\circ} 52^{\prime} \mathrm{E}\right)$ and Lady Frere ( $31^{\circ} 42 \mathrm{~S}$, $27^{\circ} 13^{\prime} \mathrm{E}$ ) were chosen on the basis of serving significant consumer market areas and having regular public transport services. Using survey map extracts on a scale of 1:50 000, circular commuter zones are constructed with a radii of $25 \mathrm{~km}$, $35 \mathrm{~km}$ and $45 \mathrm{~km}$ around each of the four towns. These are marked A,B and C respectively. For each of these commuter zones, the largest settlement with regular public passenger transport links to the various towns is selected. The settlements are labelled SA, SB and SC respectively to correspond to the three zones.

Using a household register kept by the local administrator (headman) in each of the selected settlements, a random sample of 50 households was selected for interviews. The total sample size for each commuter zone came to 200 and the overall total for the 12 sites came to 600 respondents. The sample size is deemed large enough for this type of study to avoid limitations of a small size. A structured interview schedule was designed and piloted in a rural settlement close to Queenstown in order to evaluate the validity of the instrument. The responses were checked for consistency in terms of the success with which the questions generated the particular information required. The interview focused on three types of information: shopping patterns of households, the state of public transport pric- 


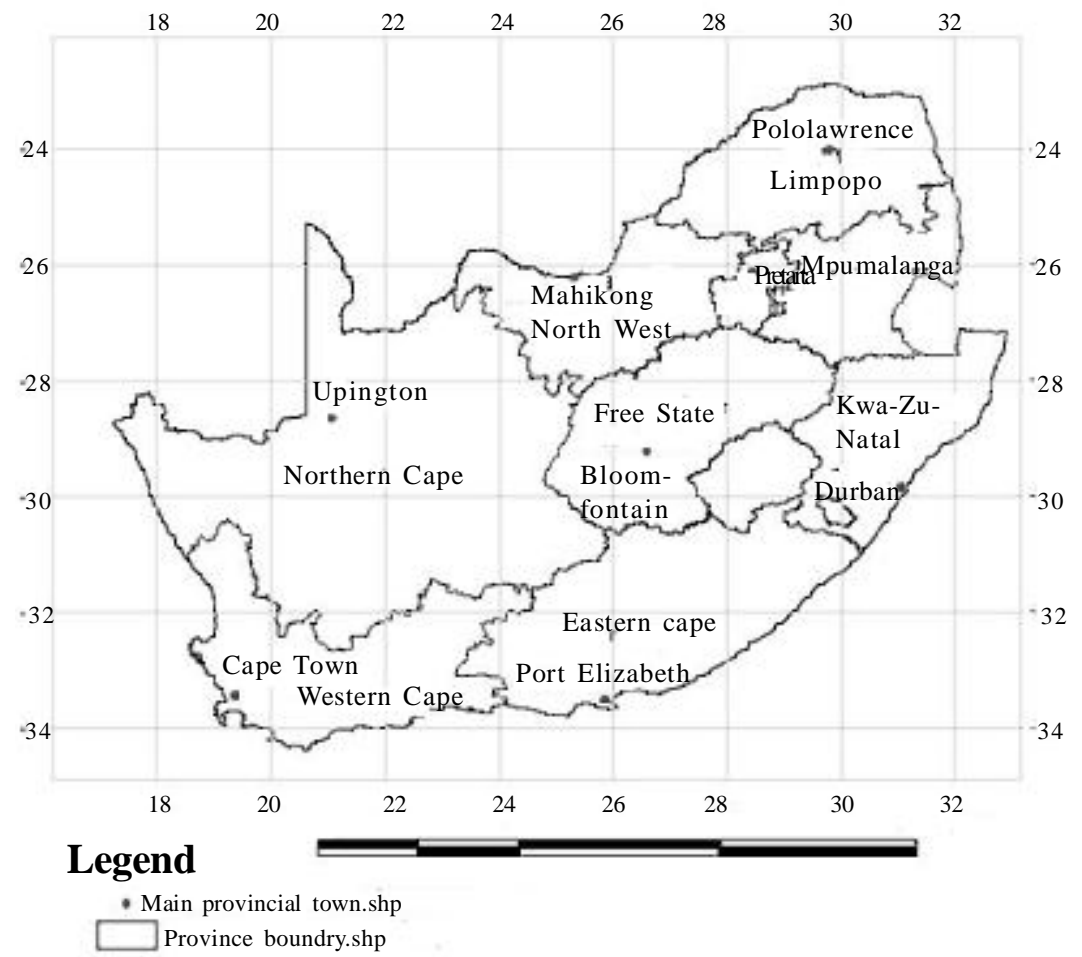

Fig. 1. South Africa- Provinces and major urban centres Source: Author

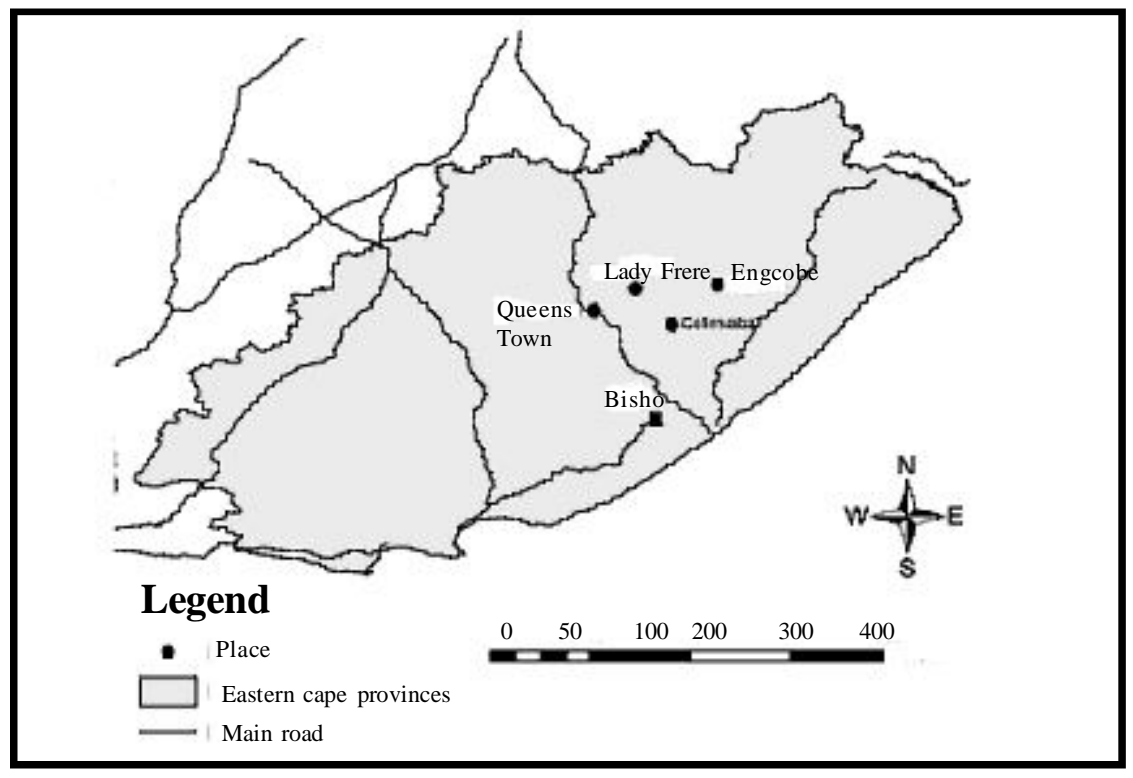

Fig. 2. The Eastern Cape Province

Source: Author 
ing and the performance of retail outlets. Household income per capita for the entire province at R13 511 (US \$1801.43) was accessed from an official publication of the Provincial Government (EDEA 2010). Using a team of pre-trained field workers, visits were made to individual households in the selected sites per commuter zone around each of the four towns to arrange appointments and to explain the nature of the research project. The confidence level was set at $95 \%$ and a census of VAT (value added tax) registered businesses was carried out in each of the four towns. The results appear in Table 1. The data from the interviews and observation was subjected to correlation analysis and the computation of the coefficient of determination.

\section{RESULTS}

At least $52 \%$ of all VAT registered outlets were in the supermarket, general dealer, and footwear and clothing category. Retail distribution in Table 1 shows that Queenstown and Mthatha are established regional centres while Engcobo and Lady Frere remain basically very small towns. The percentage dominance of the modern retail sector in the purchasing preferences of consumers is shown in Table 2, column 6 and 7 the three dominant outlet types- supermarkets and general dealers, clothing and footwear and, fruit and vegetables score a cumulative $78 \%$ of reported consumer shopping. The remaining $22 \%$ is taken up by other modern sector outlets. In column 8 , the relative size of patronage that the traditional retail sector attracts-both in town and within the study sites is indicated ranging from a mere 1\% for Queenstown (B) to 27\% for Engcobo $(\mathrm{C})$. Developments in public transport and the attraction of big business-supermarket chains, liquor stores, furniture and clothing stores- has led to a drastic drop in transaction flows between towns.

Households with working members and remittances from members of the extended family were isolated from the rest; these scored a mean trip frequency of 5.72 which is higher than for the entire 12 sample clusters. It was also reported that household with a mean family size of 6 people and over, registered on average higher trip frequencies. This would appear to indicate that family size, employment status and income per capita exert a significant impact on shopping behaviour.

Mean frequencies of household shopping trips show a higher mean score for localities in the 25 kilometre belt than for the other farther localities-indicating the shopping convenience enjoyed by households within the daily commuter belt. Correlation between household shopping trips and the effect of distance indicate in Table 3 that all the coefficients are weak and predominantly negative. This indicates that irrespective of the distance zone, shopping trips do not show a significant relationship with variations in distance. Trip frequencies generally seem to decrease with increasing distance from the nearest town but, the decrease is not radical-indicating the effect of other factors at play.

The frequency of shopping trips against variations in trip cost reveals interesting outcomes. First, as expected cost and distance are not directly related. Secondly, the low coefficients for trip cost and trips indicate the role of the intervening opportunities. In Table 3, only the coefficient for Engcobo, zone B at 0.098 and in Table 4, Queenstown, zone A at 0.147 are noteworthy. In Table 5, a summary of standard deviation values is presented for the number of household trips, distance from settlement to the nearest designated town and the return cost per

Table 1: Distribution of business activity in the study area

\begin{tabular}{lllllllllll}
\hline & $F \& A$ & $S \& G$ & $C \& F$ & $F F$ & $W H$ & $F M$ & $D S$ & $L Q$ & $F \& V$ & $H W$ \\
\cline { 2 - 9 } & $(1)$ & $(2)$ & $(3)$ & $(4)$ & $(5)$ & $(6)$ & $(7)$ & $(8)$ & $(9)$ & $(10)$ \\
\hline Engcobo & 2 & 10 & 5 & 2 & 1 & 1 & 2 & 4 & 1 & 2 \\
Lady Free & 1 & 5 & 3 & - & - & - & - & 3 & - & 2 \\
Queenstown & 6 & 20 & 15 & 6 & 3 & 2 & 2 & 6 & 2 & 3 \\
Mthatha & 5 & 22 & 10 & 5 & 3 & 1 & 5 & 5 & 3 & 4 \\
\hline Total & 14 & 57 & 33 & 13 & 7 & 4 & 9 & 18 & 6 & 11 \\
\hline
\end{tabular}

Source: Census of VAT registered business units, June 2010-Author.

Where, F\&A=Furniture and Household Appliances; S\&G=Supermarket and General Dealers; FF= Fast Food; FM=Farm machinery, tools and accessories; DS=Drug Store; F\&V=Fruit and vegetable store; HW= Hardware Store 
Table 2: Location, income, transport cost and shopping trips

\begin{tabular}{lccccccc}
\hline${ }^{7}$ Centre & ${ }^{2}$ Zone & $\begin{array}{c}{ }^{3} \text { Distin } \\
k m\end{array}$ & $\begin{array}{c}{ }^{4} \text { Mean } \\
\text { TF }\end{array}$ & $\begin{array}{c}{ }^{5} \text { Return } \\
\text { TC US } \$\end{array}$ & $\begin{array}{c}{ }^{6} \text { Stor } \\
e \text { Ch }\end{array}$ & $\begin{array}{c}{ }^{7} \text { Purchin } \\
\% \text { 's }\end{array}$ & $\begin{array}{c}{ }^{8} \text { Purch\% } \\
\text { TStores }\end{array}$ \\
\hline Engcobo & (A) & 17.20 & 3.48 & 3.9446 & $2: 3: 9$ & $60-18-04$ & 19 \\
& (B) & 31.54 & 3.60 & 4.27884 & $2: 9: 3$ & $54-20-08$ & 22 \\
Lady Frere & (C) & 42.00 & 3.20 & 7.13166 & $2: 3: 4$ & $48-21-07$ & 27 \\
& (A) & 19.70 & 4.28 & 3.8300 & $2: 3: 10$ & $66-15-09$ & 10 \\
& (B) & 30.82 & 3.32 & 4.4758 & $2: 3: 9$ & $71-10-04$ & 16 \\
Queenstown & (C) & 40.44 & 2.68 & 8.0614 & $2: 9: 10$ & $45-22-11$ & 13 \\
& (A) & 17.60 & 3.80 & 2.7170 & $2: 3: 9$ & $59-21-07$ & 13 \\
Mthatha & (B) & 29.34 & 3.56 & 5.4370 & $2: 3: 9$ & $63-17-09$ & 1 \\
& (C) & 40.84 & 2.84 & 4.5834 & $2: 9: 10$ & $65-13-07$ & 15 \\
& (A) & 21.08 & 3.82 & 3.5598 & $2: 3: 9$ & $57-25-05$ & 13 \\
\hline Total & (B) & 30.30 & 3.55 & 4.4390 & $2: 9: 3$ & $49-23-07$ & 21 \\
\hline
\end{tabular}

Where $1=$ the three urban centres constituting the study sites; $2=$ the three individual settlement clusters corresponding to a 25-35-45 kilometre distance from the urban centre; $3=$ distance in kilometres of the settlement from the urban centre; $4=$ the mean number of shopping trips per month by the household generated from individual scores from sample; 5 mean return trip cost per site; 6. the three (3) most ranked dominant store types in the shopping preference of households while 7 is a conversion of these into relative \%'s; 8 . \% purchases from the traditional retail sector outlets

Table 3: Coefficients for household monthly shopping trips and distance

\begin{tabular}{lcrr}
\hline & $A$ & $B$ & \multicolumn{1}{c}{$C$} \\
\hline Mthatha & -0.057 & -0.085 & 0.054 \\
Engcobo & -0.000 & 0.098 & -0.009 \\
Queenstown & -0.007 & 0.042 & -0.060 \\
Lady Frere & -0.023 & -0.059 & -.0 .020 \\
\hline
\end{tabular}

Table 4: Coefficients of household monthly shopping trips and cost per trip

\begin{tabular}{lrcc}
\hline & $A$ & $B$ & $C$ \\
\hline Mthatha & -0.013 & -0.156 & -0.113 \\
Engcobo & 0.022 & -0.196 & -0.078 \\
Queenstown & 0.147 & -0.138 & -0.253 \\
Lady Frere & -0.008 & -0.237 & -0.188 \\
\hline
\end{tabular}

Table 5: Standard deviation for trips, trip cost and distance

\begin{tabular}{llll}
\hline & Zone A & Zone B & Zone C \\
\hline Trips & 1.904 & 1.769 & 1.604 \\
$\begin{array}{l}\text { Distance in } \\
\text { kilometres }\end{array}$ & 3.470 & 2.167 & 2.170 \\
Cost in US \$ & 0.681 & 0.347 & 0.739 \\
\hline
\end{tabular}

shopping trip in US \$ equivalent. The highest variability is shown by the distance variable for zone $\mathrm{A}$ at 3.470 while the lowest score is recorded for Zone $C$ at 0.347 . Using the coefficient of determination, $R^{2}$ to represent the square of the
Pearson product moment correlation coefficient and with a single regressor $(\mathrm{X})$ and a corresponding response variable (y), the highest positive outcome of $R^{2}$ is at $2 \%$ for Queenstown, zone A. Using the mean per capita income of US $\$ 1801.43$ for the province as for 2010, data on individual household consolidated income was captured for all respondents. The impact of household income and family size on shopping trips generated coefficients $\mathrm{r}=0.748$ and $\mathrm{r}=0.585$ respectively indicating an $R^{2}$ of $55 \%$ and $34 \%$ respectively. The implications of these findings are discussed in the next section.

\section{DISCUSSION}

The main feature of the retail trade sector is that the traditional component is in a state of general decline- a finding that concurs with $\mathrm{Ru}-$ hiiga (2001). The decline in formal employment opportunities- following a constriction of labour uptake in agriculture and mining- has seen a mushrooming of the second economy - whose activities present additional challenges to established small retailers. There is little evidence that the traditional retail sector is set for recovery in the near future. Instead, the sector is becoming increasingly marginalised. The way retail outlets respond to the erosion of their market share (Faguenbaum et al. 2002) is very much conditioned by the way owner-managers understand the dynamics of change and competition 
(Humphrey 2007). On face value, this point to problems of entrepreneurship and business literacy- a position consistently cited in local literature- and partly explains the lack of evidence on internal restructuring and diversification at the level of individual firms in the study area. But at a deeper level, the reactions of the small traditional retail sector have to be placed in the wider context of firm entry and exit dynamics under conditions of recession, competition and changing patterns of transport access. This remains a fluid area often with wide departures between theory predictions and empirical evidence in the industry. There is evidence that in the recent past, these were generally profitable outlets but today external market forces tend to fuel buying power leakages to the modern retail sector in urban centres. These developments present a volatile market environment with stiff inter-firm competition (Humphrey 2007) between small retailers themselves and with the modern retail sector. It also presents a parallel link between the domestic and the foreign modern retail sectors. Competition stops being a simple affair between the traditional and the modern; even the domestic modern sector is under threat from newly established chain outlets originally not operating in South Africa. Traditional methods of retailing and experiences therein handed down from generation to generation are no longer the only requirement for business success. Modern retailing has to confront a rapidly evolving market environment with a greater number of players and consumer choice than the case twenty or so years ago.

The extent to which firms access business information and use this in strategic decision processes about what products to trade in, what pricing techniques to employ, what marketing strategies to use, what size and quality of labour force to employ, what level of professionalism and skill base of management will increasingly determine business performance and success. The size factor counts and as a result the largest percent of existing retail outlets, across all retailing categories will not be able to access such critical sources of information; let alone, to productively deploy the same. This finding concurs with Puccinelli et al. (2009) who advise that firms need to understand critical retail drivers that influence each stage of the consumer decision process. The traditional retail sector suffers most as a result. In the meantime, public transport may at this stage of retail development be a critical driver in changing consumer behaviour. Eventually, ownership of the private car as the dominant means of travel and accelerated urbanisation will unleash a new set of market conditions- as has already happened in Europe, Australia, Japan, South Korea, New Zealand and North America- that the retail sector will have to plan for and adapt. Current developments are therefore simply a temporary stage in the growth and development equation. Investments in retailing should by necessity be conscious of these future scenarios.

The results indicate that traditional retail outlets struggle to retain a mere $26 \%$ of spending power (see Table 2 ) split between rural based and urban based operators with the former accounting for the lion's share of patronage. This meagre amount is inadequate in providing the basis for additional business investment to upgrade the diversity of what the sub-sector can offer. With increasing marginalisation, the study area has literally been over-run by larger town based retail chains such that the modern retail sector is increasing its market control at the expense of traditional retailers. From an economic growth perspective, these developments are not negative for the area. So while the traditional retail sector may be in a state of decline and unable to generate growth multipliers in the local economic landscape, a finding that concurs with Lekhotla (2011), its marginalisation should be viewed in the wider context of market change. The expression 'constructive destruction' after Schumpter (1942: 84) who regarded the most important form of competition as that coming from the new commodity, new technology, the new source of supply and new forms of organisation is appropriate for these developments. In the meantime, the spatial-temporal implications of these developments are noted. The findings of this study point to an evolution of a growth surface increasingly linked to changes taking place in urban centres-small, medium and large and the generation of agglomeration tendencies that blur the distinction between urban and rural localities.

How have developments in transport in general and in public passenger transport in particular aided changes reported in this paper? The quality of feeder roads between the countryside and towns has not improved and indeed most of these roads become treacherously impassable 
during heavy rains. But an increase in the ownership of public passenger vehicles reported in all the four study sites in recent years and the strict control over the main routes linking towns means that the largest number of new operators has to pry along these shorter feeder roads. The result is a higher frequency of public passenger vehicles on these minor routes linking villages to the towns and the benefits of a regular transport service. The result is that all rural settlements around these towns are now accessible by road on a daily basis and higher levels of spatial connectivity between towns themselves has had an immediate effect on trips and trip generation dynamics. Access to public transport increases mean shopping trips that individuals make from own residence to town. Where transport is affordable as a result of stiff competition between bus and mini-bus operators, this reduces the role of transport as a constraint in the shopping decisions of the household. Increasing accessibility and connectivity means that rural people are no longer disadvantaged by their location. Table 2 indicates the relatively high shopping trip frequencies reported by household across different distance zones. This has accelerated the adoption of urban lifestyles simultaneously placing rural consumers beyond the shopping expectations of not only local stores but of all traditional retail outlets. Travel frequencies for individuals and for households increase together with possibilities for extending the daily commuter belt of consumers.

The role of transport development in facilitating household participation in local economic activities remains a neglected area. Yet, transport in this study appears to exert an influence that has hitherto not been much appreciated in studies of business performance and changing consumption patterns. In short, the geographical margins of the true rural localities are reduced thereby increasing the immediate market influence of individual towns. The findings of this study indicate that large households register above average shopping trips and those households with working adults or access to remittances from working family members report higher income per capita scores than the average for the province. This would appear to show that there is a close linkage between family size and income in predicting the probability of monthly shopping trips to the nearest towns. Consumer responses did not pick out the high cost of pub- lic transport as a deterrent to travel patterns: this may show that the absence of alternative sources of goods and services close to the residence of respondents leaves them with no alternative. Transport cost is hence absorbed into the normal household budget as a necessary expenditure item. This may explain why correlation analysis did not isolate it as a major control on shopping frequencies. Access to transport therefore acts as an indirect control on the shopping behaviour of consumers in the study area.

A critical component in decision processes about exit and entry behaviour (Nyström 2005) is the role of information. The results of this study highlight significant contradictions in describing the interface between retailers and consumers. The results point to a consistent failure of the traditional retail sector to rise up to the demands of the consumer market leading to a consistent pattern of declining patronage from local households. But this apparent failure has to be seen in the context of local, national and global changes sweeping through the retail industry as reported in Coe and Wrigley (2007), Grewal and Levy (2009), and Humphrey (2007).This position contradicts a significant volume of South African contemporary literature where there seems to be a belief that the small, micro and medium business sectors can be helped to remain afloat and viable simply by providing support services, training and finance (DTI 1995; LPG 2009; Ladzani 2010).

Direct implications for management across firms small, medium and large are noted. The market environment for all forms of retailing business is changing. While such change may be faster in major cities than in small and secondary towns- firms have to respond. From consumer responses, consumption behaviour is changing faster than the ability of most retail firms to keep up- constrained as they are by time, limited capitalization, experience and unpredictable outcomes. Retail outlets that will survive are those that are fast learning organisations with a tendency towards product specialisation and a strategic deployment of resources to retain a target clientele and quickly adapt to changing consumer demand. This finding agrees with Ruhiiga (2000, 2002) but contradicts the findings of Sithole (2007) who advances arguments around the removal of market barriers. Firms that hold large quantities of stock across different classes of merchandise meet problems in diversifying into newer more profit generat- 
ing retail categories. Supermarkets and general dealers have over the years perfected the retail format suitable for this brand of trading. Most general dealers will therefore transform into supermarkets, reduce their range of merchandize in order to specialize and survive or will- failing to diversify- gradually lose their niche markets.

In line with the findings, the implications are that firms which are constrained in the ability to access information about the consumer market they wish to serve- especially the changing socio-economic parameters- are handicapped in their response options. This is because without inputs from periodic market research, they are limited in their understanding of consumer behaviour today; handicapped in predicting changes in this behaviour and, constrained in mobilizing strategic resources to optimize their interactions with such a market space. It is not enough simply to blame big business for the misfortunes of most retail outlets today. On a comparative basis therefore, it would appear that the traditional retail trade sector- historically stuck in experience passed down from generation to generation, reluctant to widen ownership through share capital options, reluctant to employ professional managers, generally conservative, is slow in reacting to changes in the market place.

\section{CONCLUSION}

In conclusion, the findings show that developments in public transport have facilitated changes in consumer shopping behaviour but that the decline of traditional retailing is a product of factors that go beyond transport. Changes in retailing at the local, regional and global scales have outpaced the adaptive responses of the traditional retail sector which is increasingly losing market share to the modern retail sector. But these changes in retailing have essentially been a response to increasing consumer sophistication partly driven by the impact of globalisation. Traditional retailing is caught in a web of developments generated by internal and external market forces which limit their potential for progressive adaptation and survival.

\section{RECOMMENDATIONS}

Further research is needed to enquire into exit and entry behaviour of established firms in low-income markets, the responses of the various retail sector segments to modernisation and on the central role of market research in generating knowledge for decision-making processes. State support for the retailing segment of the small, micro and medium enterprise should target facilitating flexible adaptation to rapid change and diversification into other economic activities.

\section{REFERENCES}

Carruthers R, Krishnamani RR, Murray S 2008. Improving Connectivity: Investing in Transport Infrastructure in Sub-Saharan Africa. Summary Background Paper 7, Africa Infrastructure Country Diagnostic. New York: World Bank.

Coe NM, Wrigley N 2007. Host economy impacts of transnational retail: The research agenda. Journal of Economic Geography, 7(4): 341-371.

Coe NM, Wrigley N 2009. Introduction: Profiling the emerging multi-disciplinary literature on the globalization of retailing and its impacts. In: NM Coe, $\mathrm{N}$ Wrigley (Eds.): The Globalization of Retailing. Cheltenham: Edward Elgar Publishing.

CSIR 2005. Guidelines for Human Settlement Planning and Design. Volume 2. Pretoria: CSIR.

Dawson JA 2007. Scoping and conceptualising retailer internalisation. Journal of Economic Geography, 7: 373-397.

DOT 1996. White Paper on National Transport Policy. Pretoria: Department of Transport.

DOT 1998. Guidelines for Establishing Public Transport Demand and Associated Transport Systems in Settlements. Pretoria: Department of Transport.

DTI (Department of Trade and Industry) 1995. White Paper on the National Strategy for the Development and Promotion of Small Business in South Africa. (General Notice 213 of 1995). Government Gazette, 357(16317), 28

Faguenbaum S, Berdegué JA, Reardon T 2002. The rise of supermarkets in Chile: Effects on dairy, vegetables and beef chains. Development Policy Review, 20(4): 459-471.

Grewal D, Levy M 2009. Emerging issues in retailing research. Journal of Retailing, 85(4): 522-526.

Humphrey J 2007. The supermarket revolution in developing countries: Tidal wave or tough competitive struggle? Journal of Economic Geography, 7(4): 433-450.

Ladzani W, Natswera G 2009. Support for rural small business in Limpopo, South Africa. Development Southern Africa, 26(2): 225-239.

Lekhotla PJ 2011. Limitations on the Growth of Economic Multipliers in the Small Business Sector of the North Eastern Free State, South Africa. MA. Dissertation,Unpublished. Bloemfontein: University of the Free State.

LPG (Limpopo Provincial Government) 2009.Limpopo Employment, Growth and Development Plan. Document 3, 2004-2009. Polokwane: Limpopo Provincial Government, South Africa. 
Lombard M, Cameron B, Mokonyama M, Shaw A 2007. Report on Trends in Passenger Transport in South Africa. Halfway House, Midrand: DBSA

Mayers I, Proest S 2002. Reforming Transport Pricing: An Economist's Perspective on Equity, Efficiency and Acceptability, Acceptability. Leuven: Faculty of Economics and Applied Sciences, Center for Economic Studies, Energy, Transport and Environment, Kathorieke Universiteit, Leuven. Working Paper Series, No. 2002-12. From <http: //www.kuleuven.ac.be/ete> (Retrieved July 10, 2011)

Mwakalonge JL 2011 Trip Generation Modeling Using Data Collected in Single and Repeated CrossSectional Surveys. Washington, D.C: Transportation Research Board.

Naudé WA, Krugell WF 2004. An Inquiry into Cities and Their Role in Sub-National Economic Growth in South Africa. CESIS Electronic Working Paper Series Paper No. 28.

Nyström K 2005. Interdependencies in the Dynamics of Firm Entry and Exit. (JIBS). From< http: // www.infra.kth.se/cesis> (Retrieved on 1 May 2011).

Porter G 2007. Transport planning in Sub-Saharan Africa. Progress in Development Studies, 7(3): 251257

Puccinelli N M, Goodstein R C, Grewal D, Price R, Raghubir P, Stewart D 2009. Customer experience management in retailing: Understanding the buying process. Journal of Retailing, 85(1): 1-14.

Reardon T, Berdegué JA 2002. The rise of supermarkets in Latin America: Challenges and opportunities for development. Development Policy Review, 20(4): 71-388.

Reardon T, Timmer CP, Christopher B, Berdegué B, Berdegu $1 / 2$ J 2003. The Rise of the Supermarkets in Africa, Asia and Latin America: Challenges for Agri-food Products Suppliers. Paper Series, University of Wisconsin.

Rodriguez E, Berges M, Casellas K, Di Paolo R, Lupin B, Garrido L, Gentile N 2002. Consumer behav- iour and supermarkets in Argentina. Development Policy Review, 20: 429-439.

Ruhiiga TM 2000. Rural settlement and retail trade business in the Eastern Cape. Development Southern Africa, 17(2): 189-200.

Ruhiiga TM 2001. Pricing and buying power leakages from eastern Free State towns, South Africa. Uniqwa Research Chronicle, 3(2): 117-132.

Ruhiiga TM 2002. Modelling accelerated business growth. Southern African Business Review, 6(1): 31-37.

Ruhiiga TM 2011. Settlement structure and energy access in rural Sub-Saharan Africa. Life Science Journal, 8(S1): 46-58.

Schumpter J 1942. Capitalism, Socialism and Democracy. New York: Harper.

Schiller BR 2008. The Economy Today. New York: McGraw Hill

Schurman N,Fielder RS, Grzybowski SCW, Grund D 2006. Defining rational hospital catchment for non-urban areas based on travel-time. International Journal of Health Geographics, 5: 43.

Sithole MT 2007. Promoting the Participation of Small Businesses in the Market: How Conducive is the South African Economy? MSc. Dissertation, Unpublished. Pretoria: University of Pretoria.

STATSA 2011a. Retail Trade Sales, P6242.1 February 2011. Pretoria: Statistics South Africa

STATSA 2011b. Motor Trade, P6343.2, February 2011. Pretoria: Statistics South Africa

Verzola R 2010. Building an Economic Theory of Scarcity and Abundance. $3^{\text {rd }}$ Copysouth Workshop, International Conference on Copyright Issues, Rio de Janeiro, 28-30 June.

World Bank 2002. Cities on the Move: A World Bank Urban Transport Strategy Review. Washington. D.C: The World Bank

Wrigley NM, Lowe M 2007. Introduction: Transnational retail and the global economy. Journal of Economic Geography, 7(4): 337-340. 


\section{APPENDIX}

\section{Ref: Interview Schedule for Households}

1. Field Assistant:................ Date

2. Respondent no.

3. Fill in the location code for the settlement $\begin{array}{lll}\text { Commuter } & \begin{array}{l}\text { Name of } \\ \text { Settlement }\end{array} & \text { Nearest } \\ \text { Tone } & \text { Town }\end{array}$

4. Family size...

5. Number of working adults in the household..........

6. Number of extended family members who send periodic remittances...

7. Consolidated income per capita of the household in US \$ equivalent

US \$ 0- 501- 901- 1301- 1701- 2101- 2501- 2901- 3301+

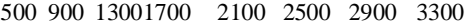

8. Average monthly shopping trips to the nearest designated urban centre.

9. Describe the nature of other trips to town on a monthly basis.

10. Describe the state of public transport between your residence and town

1 Regular, on time and reliable

2 Regular, but often unreliable due to common break downs

3 Not regular, too much time is wasted waiting for the minibus to fill up with passengers

4 Regular but slow due to too many detours along the route to town

5 Regular, reliable and fast

11. Describe the state of fares to and from town

1 Cheap and affordable

2 Cheap but fares are variable depending on whether customers have luggage

3 Expensive and difficult to afford
4 Expensive and fluctuates depending on time of the day

5 Expensive but we have no alternative

12. Are you satisfied with the number of mini-buses that serve your settlement?

1 I am very satisfied

2 I am not satisfied because the vehicles are not enough

3 I just cannot say

4 I am satisfied with the number

5 No comment

13. How does access to public transport affect your shopping?

1 We can go to town any time of the day

2 We are now able to plan our shopping trips

3 We do not have to depend only on local shops in the settlement

4 We now have access to discounts, specials and variety when we shop in town

5 Prices in town are generally better than at local shops

14. Consider changes that have occurred in public transport in the last ten (10) years: which of these best describes your experience?

1 We used to suffer because there were no vehicles serving our settlements but now we have enough mini-buses on a regular basis

2 The number of mini-buses serving the settlement have increased so fast such that we can now travel whenever we want

3 Almost no changes have occurred here: we still struggle to get transport to and from town

4 Mini-buses are now available but the fares are just too high for us; they make us poor!

5 We now have enough public passenger vehicles serving the settlement but most of these are in poor condition; they often break down and delay us 